Special Publication ACI 206, 2002

Concrete Materials Science to Application - A Tribute to Surendra P. Shah

American Concrete Institute, Farmington Hills, MI

\title{
Concrete and Sustainable Development
}

\section{By C. Meyer}

Synopsis: The United States is a country known for its wasteful use of natural resources. Efforts to correct the results of past transgressions as well as to balance economic development against legitimate concerns of conservation are pervading almost all aspects of life, including the construction industry. Concrete, being the most widely used material worldwide, is a natural target for conservation of natural resources. The cement industry is a major producer of greenhouse gases and energy user. Recent research has led to the point where numerous by-products of industrial processes with pozzolanic properties can be substituted partially for cement, such as fly ash and ground granulated blast furnace slag. Also other recycled materials are finding increased application in concrete production. For example, recycled concrete has been used successfully in numerous projects, and crushed waste glass is now available as a valuable source of aggregate, since the problem of alkali-silicate reaction has been solved. The key to commercial success is beneficiation, i.e. the targeted utilization of specific properties of the recycled material, which adds value to the end product.

Keywords: Concrete; concrete materials science; concrete technology; environmentally friendly construction; fly ash; green buildings; recycling; supplementary cementing materials; sustainable development; waste glass; waste materials. 
Christian Meyer is a professor in the Department of Civil Engineering and Engineering Mechanics at Columbia University in New York. He has worked in engineering practice for eight years before joining the faculty of Columbia University. His main interests are related to analysis and design of concrete structures and earthquake engineering. In recent years he has worked primarily in the field of concrete materials science and technology, in particular searching for ways of using waste materials to develop concrete products.

\section{INTRODUCTION}

The United States is a country blessed with enormous natural resources. This partially explains their wasteful exploitation in the past. To those who grew up in countries less blessed with such natural riches or with scarcities produced by wars or natural disasters, experiencing the wasteful use of those resources in the United States can come as something of a cultural shock.

Recycling and the reuse of natural materials have been traditionally of low priority and often nonexistent in the U.S. This is no longer the case. A dramatically different attitude can be felt today throughout the country. This change came relatively suddenly, gaining significant momentum in the early 1970s. A key event was the celebration of Earth Day in 1970, when a large part of the American public became aware of the limits of the nation's resources and grew concerned about the deteriorating environment, whether soil, water, or air. If any single picture could symbolize this awakening, it was the famous photo taken by our astronauts of "Spaceship Earth", which dramatically illustrated the fact that our planet is indeed finite in size and in resources, and that we had better learn how to live within our means. This applies particularly to Americans, who use those resources vastly out of proportion with their share of the world population.

One other reason why the American public was so slow in realizing the finiteness of its resources was the size of the country. For example, unlike in many countries in Europe, there was plenty of space available to dump its refuse and waste material. Or at least this seemed to be the case and it clearly is no longer true. Not only did the physical space available for landfills become sparse, also, legislation on the federal, state, and local levels imposed severe environmental restrictions on them. As a result, many existing landfills had to be closed, with costly cleanup measures needed for some, and it is now becoming increasingly difficult to open up new landfills.

These developments are probably nowhere as dramatic as in New York City. This largest American metropolis, with 8 million people in the five boroughs of the City proper alone, probably generates more solid waste than any other city in the world, including those with much larger populations. The Freshkill Landfill on Staten Island is the world's largest - an achievement New Yorkers have no 
particular cause to be proud of. Moreover, already filled well beyond its original design capacity, it had to be closed in 2001, making a bad situation even worse.

These and various related concerns led to the concept of sustainable development, which can be summarized as follows:

1. Remedy the mistakes of the past by cleaning up our contaminated water and soil.

2. Avoid the pollution of our air, water and soil, including the release of greenhouse gases into the atmosphere that are known to contribute to global warming.

3. Utilize natural resources, whether material or energy, at a rate no greater than at which they can be regenerated.

4. Find a proper balance between economic development and preservation of our environment, i.e. improve the living standard and quality of life without adversely affecting our environment.

These goals describe an ideal state and are obviously difficult to achieve. Yet, we do not have much of a choice, lest the liveability of our planet take a rapid turn for the worse. As the World Earth Summits in Rio de Janeiro (1990) and Kyoto (1997) demonstrated very clearly, this worldwide problem can be solved only through concerted international efforts. The industrialized countries are called upon to reduce the emission of greenhouse gases and the wasteful use of natural resources, and the developing countries need to avoid the mistakes made by the industrialized world in the past and develop their economies using technologies that make optimal use of energy and natural materials, without polluting the environment.

\section{THE ROLE OF THE CONCRETE INDUSTRY}

The construction industry is not exempt from the above-mentioned requirements. The concrete industry in particular is called upon to improve its record, because it is both a major contributor to air pollution and consumer of vast quantities of natural materials (1). For each ton of cement produced, one ton of $\mathrm{CO}_{2}$, a greenhouse gas, is released into the atmosphere. Worldwide, the cement industry produced about 1.4 billion tons in 1995, which caused the emission of as much $\mathrm{CO}_{2}$ gas as 300 million automobiles - accounting for almost $7 \%$ of the total world production of $\mathrm{CO}_{2}$ (2). Concrete is the most widely used material worldwide. Our industry has a responsibility and societal duty to make a contribution towards sustainable development that is commensurate with its size. There is still a large difference between simply declaring concrete to be a "green" (in the sense of "environmentally friendly") material and actually taking the steps necessary to achieve sustainable development.

There are two major opportunities to achieve such a goal that shall be addressed here. As portland cement production is known to require large amounts 
of energy and is responsible for the release of greenhouse gases, any effort to reduce the cement content in concrete will be beneficial. For this reason, researchers who develop cementitious materials that require comparably small amounts of energy to produce or that are waste products from industrial or combustion processes are making a major contribution to achieve this goal. The other possibility is to substitute recycled materials for aggregate or reinforcement. This includes the recycling of concrete itself. By one estimate, the concrete industry is currently consuming 8 billion tons of natural material each year (3). Any efforts to reduce such dependence of virgin materials will therefore be a contribution towards sustainable development. In the following, some of the recent advances in both areas shall be discussed to point out directions for future research to make concrete a more environmentally friendly material.

A separate approach towards conserving natural resources is the targeted increase in durability, because more durable structures need to be replaced less frequently. Such durability increase can be achieved by choosing appropriate mix designs and selecting suitable aggregates and admixtures. This issue has been discussed in detail in (1) and shall not be dealt with here any further.

\section{CEMENT SUBSTITUTES}

Cement is the key component of concrete that binds the other components together and gives the composite its strength. A considerable amount of work has been reported in the literature on how to use waste products of combustion or industrial processes as supplementary cementitious materials $(3,4,5)$. Because of their cementitious or pozzolanic properties these can serve as partial cement replacement. Ideally, the development of such materials serves three separate purposes simultaneously. On the one hand, waste byproducts have an inherent negative value, as they require disposal, typically in landfills, subject to tipping fees that can be substantial. When used in concrete, the material's value increases considerably. The increase in value is referred to as "beneficiation". As this supplementary cementitious material (SCM) replaces a certain fraction of the cement, its market value may approach that of cement. A second benefit is the reduction of environmental costs of cement production in terms of energy use, depletion of natural resources, and air pollution. Also, the tangible as well as intangible costs associated with landfilling the original waste materials are eliminated.

Finally, such materials may offer intriguing additional benefits. Most concrete mixes can be engineered such that the SCM will give the mix certain properties (mechanical strength, workability, or durability) which it would not have without it. It is the challenge for the concrete technologist when developing a mix design, to combine these three different goals in an optimal way such that the economic benefits become transparent. The key task is to turn waste material with a large inherent negative value into a potentially valuable product. The increase in value should be both real, in terms of converting a liability into a commodity with an 
increased market value, as well as intangible in terms of reduced environmental costs. The fundamental challenge for the researcher is to identify waste materials with inherent properties that lend themselves to such beneficiation. Below, a few examples shall be mentioned.

Fly ash is the byproduct of coal burning power plants and is known to have excellent pozzolanic properties $(4,5)$. Its use in the concrete industry has a long and successful tradition. However, in terms of the ratio of fly ash utilized to fly ash produced, there remains considerable room for improvement. For example, of the 60 million tons of ash produced in 1995 in the U.S., only 8.1 million tons were utilized (2). India beneficiated only 2 million of the 57 million tons produced there in the same year. This latter figure is worrisome, because India, like many other developing countries, is expected to increase considerably its coal-based power generation and cement production capacities in the years to come. Without a major concurrent effort to make productive use of the ash, the environmental pollution can be expected to worsen at a comparable rate $(2,3)$.

The use of fly ash as partial cement replacement is not without its challenges. There are limits as to how much of the cement may be replaced. $20 \%$ is an often mentioned and easily achieved goal. Malhotra has shown that as much of $60 \%$ cement replacement by ASTM Class F fly ash is feasible (6). Recent research has shown that it is possible to replace $100 \%$ of the cement with chemically selfactivated fly ash (7). However, the activators proposed so far either need to be added in unreasonable amounts or are relatively expensive. A major point of concern is the generally slow strength development of fly ash concretes. However, in construction practice, high early strength is important only for some projects. In many others, such as those involving mass concrete, slow strength development may even be an advantage, as it generates lower heat of hydration rates. Another potential problem is quality control, because the exact properties of the fly ash may change from batch to batch, depending on the source material. Therefore, concrete containing large amounts of fly is less likely to be suitable for architectural or other applications with specific esthetic requirements. On the positive side, fly ash is known to suppress alkali-silica reaction to some extent.

Ground granulated blast furnace slag is another industrial waste product with beneficial properties that have been well documented in the literature. The glassy granular material is formed when molten blast-furnace slag is rapidly chilled in water. The material is then ground to specification. Whereas in the past it was typically deposited in landfills, because of its excellent cementitious properties, it is now being used as a partial cement substitute. If it is of the proper quality and used in properly designed mixes, it can increase the strength, durability and other properties of the end product (8).

Possibly the greatest success story in this regard is that of condensed silica fume. A byproduct of the semiconductor industry, this siliceous material is known to improve both strength and durability of concrete to such an extent that modern 
high-performance concrete mix designs as a rule call for the addition of silica fume. Even though the material is difficult to handle because of its extreme fineness, its benefits are so obvious that its market value is considerable. This makes silica fume a classic example of waste material beneficiation.

A final example is solid waste incinerator ash. To be specific, solid waste incinerators generate both bottom ash and fly ash. Because the fly ash is typically contaminated with various hazardous substances, its disposal creates additional problems and also complicates its beneficiation. Some technologies that have been proposed render the toxic elements harmless by vitrification, which requires large amounts of energy (9). If less effective detoxification methods are employed, extensive leaching tests need to be performed to assure that the harmful substances cannot leach out under most service exposure conditions. Protocols for such tests can simulate actual service conditions only inadequately, and therefore environmental protection agencies prescribe a variety of different tests (10).

\section{RECYCLED AGGREGATE}

Aggregate constitutes approximately $70 \%$ of concrete volume. Worldwide, this amounts to billions of tons of crushed stone, gravel, and sand that need to be mined, processed, and transported. In some parts of the country, suitable gravel pits and sources of construction grade sand are depleting, while the opening of new sources requires time-consuming environmental impact statements and the procuring of the necessary permits, aside from the need to overcome public opposition. For this reason, in certain geographic regions such as Long Island of New York State, the search for alternate sources of aggregate is increasingly becoming a necessity.

The substitute material that comes to mind first is recycled concrete. Construction debris and demolition waste constitute $23 \%$ to $33 \%$ of municipal solid waste, and demolished concrete contributes the largest share of this waste material (11). A sizeable amount of literature is available on the use of recycled concrete (12), and in North America, several projects have been completed successfully $(11,13)$. The use of recycled concrete poses many interesting research problems. The fines and dust produced during demolition and crushing, together with the pore structure of old concrete, increase the water absorption, which has to be considered in the mix design. An additional challenge is posed by the quality control, due to the wide range of material properties. Compared with the properties of virgin material, those of recycled concrete are not as easily controlled. The material may be contaminated from various sources. As a result, it is typically of lower quality compared to virgin material. But unless high-strength or high-performance concrete is called for, the performance specifications of the end product may be achievable just as well with reprocessed concrete or a blend of virgin and reprocessed material. 
The economics of recycled concrete depends on a number of factors. Since virgin material is generally very inexpensive, it is not easy to offer reprocessed concrete at a comparable price. But as transportation constitutes a major cost component of aggregate, the location of a suitable source of virgin material and the distance to the nearest landfill for the demolished concrete are likely to be decisive factors in determining whether the recycling of concrete is economical or not. Even with the avoidance of tipping fees, the costs of crushing and processing the old concrete are likely to reduce profit margins to such an extent, that additional economic incentives may be needed for a producer to use recycled concrete. For example, tax credits for recycled material content can offer this additional incentive. Thus, the real challenge to the researcher is again the search for properties of recycled concrete that virgin material does not have and that lend themselves to beneficiation.

Another source of aggregate is waste glass. Unlike in many European countries, separation of post-consumer glass by color in major U.S. metropolitan areas is the exception. As it is difficult for the glass industry to use mixed-color cullet, most of such cullet at this time finds its way into landfills. There are no significant markets for such glass, which is more or less contaminated with paper, bottle caps, and organic material from residuals of the original contents. The use of glass as an aggregate for concrete has been contemplated some time ago, but those early efforts have been unsuccessful because of the alkali-silica reaction (ASR) problem. A major research program at Columbia University was undertaken to study this problem in great detail, and various solutions of the problem are now available (14-17).

A considerable effort has been made to investigate the economic aspects of using waste glass as aggregate. The key to success lies again in the extent to which the special properties of the glass are exploited. For this purpose, we may distinguish between "commodity" and "value-added" products. The primary objective of commodity products is to utilize as much waste glass as possible. An example is the concrete masonry block, which is typically mass-produced in highly automated facilities with good quality control. It is possible to replace part of the fine aggregate by glass, because it was found that finely ground glass particles passing US standard sieve \#100 cause only negligible ASR-induced expansions in the mortar bar test according to ASTM C 1260. The naked eye cannot distinguish glass particles of such size from regular sand. The economics of such substitution is questionable, because ordinary sand is relatively inexpensive, whereas the glass needs to be crushed and washed to remove the harmful sugars and other contaminants.

Very finely ground glass powder passing mesh $\# 400$ has been shown to have pozzolanic properties, so that it may be used as partial cement substitute. Since such fine powder is generated as dust during crushing anyway, the economics are improved if both part of the sand and cement are replaced at the same time. 
The economic picture changes dramatically, when the special properties of the glass are exploited in "value-added" products. Aside from its pozzolanic property, glass has indeed some properties that make it quite special (17):

- Because it has basically zero water absorption, it is one of the most durable materials known to man. With the current emphasis on durability of high-performance concrete, it is only natural to rely on extremely durable ingredients.

- The excellent hardness of glass gives the concrete an abrasion resistance that can be reached only with few natural stone aggregates.

- For a number of reasons, glass aggregate improves the flow properties of fresh concrete, so that very high strengths can be obtained even without the use of superplasticizers.

- The esthetic potential of color-sorted post-consumer glass, not to mention specialty glass, has barely been explored at all and offers numerous novel possibilities for design professionals.

One example of a value-added product, in which all of these special properties are exploited, are decorative terrazzo tiles. Such tiles typically use relatively expensive aggregate that often is imported. Crushed waste glass, even if color sorted and washed, can easily compete with such aggregate. As a result, glass concrete tiles are already being mass-produced commercially. Other examples, still under development, are wall panels, building façade elements, table-top counters, benches, planters, etc. Architects, designers, and artists are intrigued by the potential of this new material. Once realized in such high-end products, the glass becomes a valuable resource, and the goal of beneficiation has been achieved completely.

Dredged material is a further important example that is being evaluated for use in concrete (18). One of the most pressing problems confronting most major seaports of the world is the need for dredging in order to keep the shipping lanes open. Until recently, the dredged material was simply disposed of in the open ocean. But since it may be highly contaminated, national legislation and international agreements are now prohibiting such practice. The Port Authority of New York and New Jersey, for example, is now facing the task of properly disposing of up to four million cubic yards of dredged material each year. The material consists mostly of clays and silts, much of it highly contaminated with oils, heavy metals, PCB's and other toxic substances. A major research project is currently underway at Columbia University to search for a beneficiation technology that renders the toxic components harmless. It is contemplated to use the treated material as aggregate or filler in concrete, aside from other applications. The research challenge is formidable, because the bulk of the material does not readily lend itself to utilization in concrete. 
The economics of this example is unlike that of the others, because of the very large negative value inherent in the material. If the processing cost can be kept well below that of disposal in specially designed facilities, the retail value of the end product becomes less significant. Used as an ingredient in concrete, it would have again achieved the goal of adding value. A solution of this pressing problem is not only of concern to environmentalists. The economic well-being of entire regions may depend on it.

Waste wood, such as sawdust and shavings, has also been used to produce specialty concrete products (19). Also in this case, potentially adverse chemical reactions between the sugars and other organic substances in the wood and the cement present a challenge that needs to be addressed. The primary advantage of waste wood aggregate is the low weight and high thermal insulation value of the material. The economics depends on several factors, including the geographical area where the material originates. In the U.S., much of the material is utilized in manufacturing of particle boards. But if products can be developed that utilize the special properties of the wood in concrete, commercialization should be possible.

\section{CONCLUSIONS}

The concrete industry is a major contributor to air pollution and user of natural resources. As such it bears a special responsibility to make a contribution towards sustainable development that is commensurate with its size. It can do so by pursuing three goals:

1. Searching for cement production technologies that are less energyintensive and cause less air pollution. Since such technologies will not be available in the foreseeable future, the more realistic approach is to reduce the need for portland cement, primarily by increased use of supplementary cementitious materials, especially waste materials.

2. Replacing concrete ingredients by recycled materials, such as recycled concrete or waste glass.

3. Through careful concrete mix design and prudent choice of admixtures, improve the durability of structures such that they need to be replaced less frequently.

The development of practical technologies requires the solution of technical and economic problems. It appears that often the technical problems are easier to solve, because the required research is based on sound scientific principles and methods. The commercial aspects of product development are subject to numerous economic influences and sometimes to political and psychological ones as well. The economic feasibility is determined primarily by the forces of supply and demand, neither of which can be controlled easily. These relationships have to be well understood to assure commercial success. 
There are a few success stories for illustration. They all have in common that certain inherent properties are exploited in an optimum way to create value. By utilizing the pozzolanic properties of fly ash, for example, a waste material of the coal-burning power industry with inherent negative value is converted into a value-added material with a market value close to that of the cement it replaces. The benefits of silica fume for high-performance concrete are so obvious that this by-product of the semiconductor industry achieves a market value that is even higher. Color sorted waste glass gives rise to new decorative and architectural concrete applications and thereby achieves a market value comparable to that of the high-end aggregates used for specialty products.

In each case, the market value will be determined partially by the competing materials on strictly economic terms and often by political considerations as well. For example, if the political process determines that increased recycling and reuse of resources is desirable, legislation can promote this with tax incentives or outright requirements. For example, the Federal Government can require that a certain percent of recycled material be used on all federal construction projects. Such a requirement changes the economics of reprocessing technologies. But the better the inherent properties of the materials are utilized, the less dependence on legislative or regulatory initiatives is needed for such technologies to be commercially successful.

As a final point, it should be stressed that our educational system can make a useful contribution towards achieving the goals stated above. Our colleges and universities have already been called upon to increase their students' awareness of societal issues. As our profession reaches a more and more mature state, the educational emphasis is bound to shift away from some of the traditional areas of study anyway, as these will be covered more and more by computer-aided technologists. By stressing fundamental materials science and engineering and basic principles of sustainable development, educators can help prepare the next generation of engineers for a changing world, which will be much less tolerant of the old wasteful ways of using our natural resources.

\section{REFERENCES}

1. Gjorv, O.E. and Sakai, K., eds., Concrete Technology for a Sustainable Development in the $21^{\text {st }}$ Century, E\&FN Spon, London, 2000.

2. Malhotra, V.M., "Role of Supplementary Cementing Materials in Reducing Greenhouse Gas Emissions", in Concrete Technology for a Sustainable Development in the $21^{\text {st }}$ Century, O.E. Gjorv and K. Sakai, eds., E\&FN Spon, London, 2000. 
3. Mehta, P.H., "Concrete Technology for Sustainable Development - An Overview of Essential Elements", in Concrete Technology for a Sustainable Development in the $21^{\text {st }}$ Century, O.E. Gjorv and K. Sakai, eds., E\&FN Spon, London, 2000.

4. Fly Ash, Slag, Silica Fume and Other Natural Pozzolans, Proceedings, $6^{\text {th }}$ International Conference, Special Publication 178, American Concrete Institute, Farmington Hills, MI, 1998.

5. Fly Ash, Slag, Silica Fume and Other Natural Pozzolans, Proceedings, $5^{\text {th }}$ International Conference, Special Publication 153, American Concrete Institute, Farmington Hills, MI, 1995.

6. Malhotra, V.M. and Ramezanianpour, A.R., Fly Ash in Concrete, $2^{\text {nd }}$ Ed., CANMET, Energy, Mines and Resources Canada, Ottawa, Canada, 1994.

7. Samadi, A. "Treatment of Fly Ash to Increase its Cementitious Characteristics", PhD Dissertation, Drexel University, Philadelphia, PA. 1996.

8. Sehgal, J.P., "Environmentally Friendly Concrete", The Concrete Industry Board Bulletin, New York, March 2001.

9. ASME/Bureau of Mines Investigative Program on Vitrification of Residue from Municipal Waste Combustion Systems, American Society of Mechanical Engineers Report CRTD-24, 1993.

10. Hohberg, I., de Groot, G.J., van der Veer, A.M.H., and Wassing, W., "Development of a Leaching Protocol for Concrete", Waste Management 20 (2000) 177-184.

11. "Recycling Concrete Saves Resources, Eliminates Dumping", Environmental Council of Concrete Organizations, Skokie, IL, 1997.

12. Hansen, T.C., ed., Recycling of Demolished Concrete and Masonry, RILEM Report 6, E\&FN Spon, London, 1992.

13. "Recycling Concrete Pavements", Concrete Paving Technology, TB-014P, American Concrete Pavement Association, Skokie, IL, 1996.

14. Meyer, C. and Baxter, S., "Use of Recycled Glass for Concrete Masonry Blocks", Final Report to New York State Energy Research and Development Authority, Albany, NY, Report 97-15, Nov. 1997.

15. Meyer, C. and Baxter, S., "Use of Recycled Glass and Fly Ash for Precast Concrete", Final Report to New York State Energy Research and Development Authority, Albany, NY, Report 98-18, Oct. 1998. 
16. Jin, W., Meyer, C., and Baxter, S., "Glascrete - Concrete with Glass Aggregate", ACI Materials Journal, March-April 2000.

17. Meyer, C., "Recycled Glass - From Waste Material to Valuable Resource", Recycling and Reuse of Glass Cullet, R.K. Dhir et al, eds. Thomas Telford, London, 2001.

18. Millrath, K., Kozlova, S., Shimanovich, S., and Meyer, C., "Beneficial Use of Dredge Material", Progress Report prepared for Echo Environmental, Inc., Columbia University, New York, Feb. 2001.

19. Gliniorz, K.-U. and Natterer, J., "Structural Elements of Wood Lightweight Concrete" (in German), Report IBOIS 00:03, Ecole Polytechnique Federale de Lausanne, March 2000. 